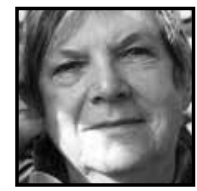

\title{
Commentary Being Hospitable to Teacher Research: A Challenge for the Academy
}

\author{
Susan Groundwater-Smith, University of Sydney
}

\begin{abstract}
In my brief contribution to this edition of LEARNing Landscapes, focusing as it does upon teacher research, integrating action, reflection, and observation, I have chosen to discuss, in particular, the right of teacher research to be recognized and affirmed by the academy in the form of hospitality; a right that is being compromised more and more by the burgeoning neo-liberal culture that dominates so many of our institutions. I argue, in spite of the constraints that are put in its way, that teacher research makes a significant contribution to the development of professional knowledge and, like other aspects of professional practice, is also subject to those parameters that determine quality.
\end{abstract}

\section{Hospitality: A Right to Visit or a Right to Belong}

ospitality is a tricky word and who no better to draw our attention
to its difficult nature than Jacques Derrida. In his provocative article,
"Hostipitality," Derrida (2000) juxtaposes hospitality with hostility and reminds us of the ways in which the two actions sit alongside each other, cheek by jowl. In writing this, in concert with much else of his work, he asserts that hospitality signals that the stranger should not be treated with hostility, but that there can be no such thing as an "unconditional welcome" (p. 4). Drawing on Kant, he sees the host remaining the master in his or her own domain, thus defining the conditions of hospitality. The "other," the guest, the stranger, is subject to the desires of the host who may say: 
'Make yourself at home', this is a self-limiting invitation ... it means: please feel at home, act as if you were at home, but remember, this is not true, this is not your home, but mine and you are expected to respect my property. (Derrida in conversation with Caputo, 2002, p. 111)

In this short piece I argue that universities, by their nature residing in a neo-liberal world, have offered a limited hospitality to the kind of research and publication that teachers and their academic mentors may undertake. They have accorded a right to visit, but not necessarily a right to belong (Still, 2010).

It could be asserted that teacher research is a counter to the oppressive force of the audit culture that is in such ascendancy in the university of today, dominated as it is by league tables determined by various research assessment exercises. Thornton (2012) has outlined the homogenizing practices of neo-liberalism in relation to knowledge production and commodification in universities with academics reduced to auditable performers. In the context of faculties of law, Thornton writes of the pressure to be productive where the aim is "merely to produce an auditable output with scant regard for the substance of intellectual worth" (p. 176). Metrics used to score research productivity in professional faculties take little or limited account of publications that have currency in the actual field of practice. Unfunded research, or research that attracts modest funding, is held to be of little worth.

In the body of this article I shall ask, can teacher research cross the threshold and be welcomed into a more hospitable university sector, can it result in knowledge that counts?

\section{Professional Knowledge That Counts}

In addressing the matter of professional knowledge that counts we need to ask ourselves the following four questions:

1. Is professional practice that is research informed an improvement upon that which is research applied?

2. What is the contribution that is made by professional research in and from the field to our quantum of professional knowledge?

3. What is the contribution that academic practitioners may make in working alongside their colleagues in the field as facilitators and co-researchers?

4. How do we judge the quality of such research? 


\section{Research Informed and Research Applied}

Lingard and Renshaw (2010) take a stance resisting teachers as translators or interpreters of educational research done by others where they are at best only informants and at worst passive recipients; that is where essentially they apply the results of research done by others. Rather, they argue for the professionals in the field to engage fully by having a "researcherly disposition" that enables them to be active inquirers, while at the same time, academics should have a "pedagogical disposition" that takes teacher research seriously and examines how it might relate to both theory and practice.

In our contribution to Methodological Choice and Design (Groundwater-Smith \& Irwin, 2011), we argued that critical to practice in professional fields is the need to seek an understanding that transcends a technical insight, whose tools are required to undertake that practice effectively. Authentic understanding is one that leads practitioners to pose the difficult questions regarding the evolution of that practice and its consequences. We drew upon the late Lawrence Stenhouse $(1975,1979)$ who advocated, within the field of education, that teachers evolve a self-critical, purposeful examination of practice for the benefit of both themselves and their students. He concluded his chapter upon Teacher as Researcher in this way:

For in the end it is difficult to see how teaching can be improved or how curriculum proposals can be evaluated without self monitoring on the part of teachers. A research tradition which is accessible to teachers and which feeds teaching must be created if education is to be significantly improved. $(1975$, p. 165)

Building upon the work of Stenhouse and his colleagues at the Centre for Applied Research in Education (CARE) at the University of East Anglia, scholars from the UK, Canada, Australia, and the USA developed forms of teacher inquiry that took account of both the circumstances of a given classroom and school and those of systems themselves; for example, Cochran-Smith and Lytle (2009) characterized "inquiry as stance" in this way:

Working from and with an inquiry stance, involves a continual process of making current arrangements problematic; questioning the ways knowledge and practice are constructed, evaluated and used; and assuming that part of the work of practitioners individually and collectively is to participate in educational and social change. (p. 121) 
By moving in this direction it became clear that not only were those supporting teacher research moving from the notion of applying research to practice, but also towards it, making a substantial contribution to knowledge about practice in a given field, a knowledge that could and should be acceptable to the academy.

The contribution that is made by professional research in and from the field to our quantum of professional knowledge. In their often quoted seminal work, The New Production of Knowledge, Gibbons et al. (1994) argue that knowledge production has been transformed. They distinguish between Mode 1 knowledge that is generated within the academy, or research establishments, and I would argue, is welcomed and applauded by the academy; and Mode 2 knowledge that is created in broader, transdisciplinary social and economic contexts, but nonetheless is identified as legitimate and thus admissible. Having made this distinction, Gibbons and colleagues subscribed to the principle that in whichever Mode, the knowledge was produced through research, whether basic or applied, it was in the hands of some kind of research community.

More recently, Nowotny, Scott, and Gibbons (2003) have argued that judging the worth of the Mode 2 Knowledge is in fact no longer the exclusive province of the academy. Indeed, they continue by asserting that the research game is being joined by more and more players. Furthermore, it has been argued that we are now in the realm of Mode 3 knowledge (Groundwater-Smith \& Irwin, 2011). Indeed, this very digital journal, LEARNing Landscapes, built as it is upon an emergent participatory culture of partnerships, collaboration, inclusion, and multiple voices (Jenkins, Clinton, Purushotma, Robinson, \& Weigel, 2006), is an example of networked knowledge, built upon a collective and mutually respectful enterprise.

Returning for a moment to Jacques Derrida, Cornell (2007) quotes him having written regarding the future:

It is a matter of looking for something that is not yet well received, but that waits to be received. And one may possess a kind of flair for that which, going against the current, is already in touch with possible reception. (Derrida in Cornell, p. 102)

While Derrida speaks to a future that heeds the voices of minorities, it is possible to also conceive of a future in the academy where professional knowledge that is developed from practitioner research may be not only accepted, but also honoured. This is surely a role for the academics in professional faculties, that they alongside their colleagues in the field become advocates, acting not just as mentors, but also as co-researchers. 
The contribution that academic practitioners may make in working as facilitators and co-researchers. All too often it is the case that where academic practitioners work alongside their field-based colleagues, the task is seen as a transactional one. Acting exclusively as a facilitator is thus in the ascendancy. In reflecting on this, GroundwaterSmith, Mitchell, Mockler, Ponte, and Ronnerman (2013) sought for a bona fide partnership in the form of all parties being co-researchers requiring mutual trust, accountability, sustainability, and transparency that may be best achieved through dialogue and debate. We argued that for partnership to take account of not only the events under scrutiny, but also for the physical, social, political, and geographic contexts in which they occur, it was essential that the relationship be governed by deep respect, each for the other. Not only that, but a respect for the quality of the inquiry being undertaken.

Judging the quality of teacher research conducted in partnership with the academy. Furlong and Oancea (2005), under the auspices of the ESRC in England, looked in particular at strategies for developing a framework for assessing quality in applied and practice-based educational research. They recognized the complex interaction between academic researchers and field-based practitioners who will themselves be engaged in systematic inquiry. In other words, they saw that there was a blurring of the boundaries between the researcher and the researched. However, there was little recognition of the very different worlds in which the various parties might work and how, in particular, universities might be more welcoming of practitioner researchers.

The framework sought to establish four dimensions of quality: epistemic; technological; capacity development and value for people; and, economic. While it would be difficult to argue with these dimensions, it is possible to insert into the discussion a fifth important, missing dimension that relates to ethical practice as a determinant of quality (Groundwater-Smith \& Mockler, 2008). In this context a series of broad, overriding "ethical" guidelines for practitioner research, conducted in concert with academic colleagues, were established. Some of these are linked to a traditional conceptualization of research ethics, while others flow from the discourse of the ethical professional, these being:

- That it should observe ethical protocols and processes: Practitioner research undertaken by those in the field, in concert with those in the academy, is subject to the same ethical protocols as other social research. Informed consent should be sought from participants, whether students, service users and providers, parents or others, and an earnest attempt should be made to "do no harm." 
- That it should be transparent in its processes: One of the broader aims of practitioner research lies in the building of community and the sharing of knowledge and ideas. To this end, practitioner research should be "transparent" in its enactment, and practitioner researchers accountable to their community for the processes and products of their research.

- That it should be collaborative in its nature: Practitioner research should aim to provide opportunities for colleagues to share, discuss, and debate aspects of their practice in the name of improvement and development. The responsibility of "making sense" of data collected from within the field of one's own practice (through triangulation of evidence and other means) relies heavily on these opportunities.

- That it should be transformative in its intent and action: Practitioner researchers engage in an enterprise which is, in essence, about contributing to both transformation of practice and transformation of society. Responsible and ethical practitioner research operates in such a way as to create actionable, actioned outcomes.

- That it should be able to justify itself to its community of practice: Engaging in practitioner research involves an opportunity cost to the community. To do well, requires time and energy that cannot be spent in other professional ways. The benefits must be commensurable with the effort and resources expended in the course of the work, which necessarily will require collaboration and communication.

\section{Conclusion}

Throughout this discussion I have argued that teacher researchers should not be seen as supplicants to universities, begging for recognition and admission, but as having a right to belong to the research-based community of practice, and that, in turn, universities should act as hospitable hosts. In the edition of LEARNing Landscapes that follows, there is ample evidence that this is critical professional work, leading to both the development of professional knowledge as well as informing how it may be best enacted. Surely, this is a legitimate task for university faculties in professional fields. The conclusion that I arrived at some eight years ago still stands: 
We need to learn to tolerate ambiguity and uncertainty and recognise that there are no 'silver bullets' that will provide ready-made solutions to complex problems. We need to be prepared to analyse and challenge cultural formations in embedded practices in the field. We need to acknowledge difference and to eschew seeking for consensus at all costs. Finally, we need to recognise that professional learning resulting from authentic partnerships is enriching, powerful and in the best of worlds emancipatory. If we can open our minds and hearts, heads and hands to each other we shall be the richer for it. (Groundwater-Smith, 2007)

\section{References}

Caputo, J. (2002). Deconstruction in a nutshell: A conversation with Jacques Derrida. New York: Fordham University Press.

Cochran-Smith, M., \& Lytle, S. (2009). Inquiry as stance: Practitioner research for the next generation. New York: Teachers College Press.

Cornell, D. (2007). The gift of the future. In C. Douzinas (Ed.), Adieu Derrida (pp. 101-108). New York: Palgrave Macmillan.

Derrida, J. (2000). 'Hostipitality'. Angelaki: Journal of the Theoretical Humanities, 5(3), 3-18.

Furlong, J., \& Oancea, A. (2005). Assessing quality in applied and practice based educational research: A framework for discussion. Oxford: Oxford University Department of Educational Studies.

Gibbons, M., Limoges, C., Nowotny, H., Schwartzman, S., Scott, P., \& Trow, M. (1994). The new production of knowledge: The dynamics of science in research in contemporary societies. London: Sage.

Groundwater-Smith, S. (2007). Authentic partnerships: Trust and risk. Keynote address, Liverpool Learning Networks Research Centre for Lifelong Learning, University of Liverpool, 12th October.

Groundwater-Smith, S., \& Irwin, J. (2011). Action research in education and social work. In L. Markauskaite, P. Freebody, \& J. Irwin (Eds.) Methodological choice and design (pp. 57-70). Rotterdam: Springer.
Groundwater-Smith, S., Mitchell, J., Mockler, N., Ponte, P., \& Ronnerman, K. (2013). Facilitating practitioner research. London: Routledge.

Groundwater-Smith, S., \& Mockler, N. (2008). Ethics in practitioner research: An issue of quality. In J. Furlong \& A. Oancea (Eds.), Assessing quality in applied and practice-based research (pp. 79-92). London: Routledge.

Jenkins, H., Clinton, K., Purushotma, R., Robinson, A., \& Weigel, M. (2006). Confronting the challenges of participatory culture: Media education for the 21st century. Online article. Retrieved from: http:// henryjenkins.org/2006/10/confronting _the_challenges_of.html

Lingard, B., \& Renshaw, P. (2010). Teaching as a research-informed and research informing profession. In A. Campbell \& S. GroundwaterSmith (Eds.), Connecting inquiry and professional learning in education: International perspectives and practical solutions (pp. 26-39). London: Routledge.

Nowotny, H., Scott, P., \& Gibbons, H. (2003). Mode 2 revisited: The new production of knowledge. Minerva, 41, 179-194.

Stenhouse, L. (1975). An introduction to curriculum research and development. London: Heineman Educational Books Ltd. 
Stenhouse, L. (1979). Research as a basis for teaching. Inaugural Lecture University of East Anglia. In Stenhouse, L. (1983), Authority, education and emancipation. London: Heinemann Educational Books.
Still, J. (2010). Derrida and hospitality: Theory and practice. Edinburgh: Edinburgh University Press.

Thornton, M. (2012). Privatising the public university. London: Routledge.

Susan Groundwater-Smith is an Honorary Professor in the Faculty of Education and Social Work at the University of Sydney. She has a long history of undertaking action research with teachers in schools and educators in cultural institutions such as museums and libraries. She convenes the Coalition of Knowledge Building Schools, a hybrid collection of schools located in the Sydney Metropolitan Area whose purpose is to engage in systematic inquiry in and across the membership. In addition, Susan has become active in advocating for student voice in educational research and has recently co-authored two books in this area: Mockler, N. \& Groundwater-Smith, S. (2015). Engaging With Student Voice in Research, Education and Community: Beyond Legitimation and Guardianship. Rotterdam: Springer; Groundwater-Smith, S., Dockett, S., \& Bottrell, D. (2015). Participative Research With Children and Young People. London: Sage. 